\title{
A FORMAÇÃO E A PRÁTICA DE OFICINEIROS EM ESCOLAS COM JORNADA AMPLIADA
}

\author{
Renata Portela Rinaldi \\ José Gilberto Spasiani Rinaldi2
}

\section{RESUMO}

O artigo trata de alguns aspectos relevantes para uma compreensão da política de educação integral, naquilo que se refere à formação de professores. Trazemos para o debate questões acerca da formação e da prática de oficineiros nas escolas com jornada ampliada valendo-nos de uma pesquisa realizada sobre um programa de educação integral, em âmbito municipal, desenvolvido no estado de São Paulo. Participaram da pesquisa oitenta e seis oficineiros atuantes no programa $(N=86)$. $O$ procedimento de coleta de dados foi o registro narrativo, seguido pelo tratamento e análise a partir da técnica do Discurso do Sujeito Coletivo (DSC), produzido com o apoio do software Qualiquantisoft. Os resultados demonstraram que a formação docente aparece de maneira tímida e superficial na produção de textos das políticas para educação integral, o que pode apontar para "velhos" problemas que se evidenciam no campo da formação de professores, por exemplo, o desenvolvimento de estratégias de formação continuada para remediar os vazios derivados da insuficiência dos cursos de formação inicial ou mesmo como um paliativo para atender às novas demandas da escola quanto à preparação dos profissionais, nem sempre professores com formação prévia, que assumem as atividades didático-pedagógicas no contraturno nas escolas com jornada ampliada.

Palavras-chave: Formação de professores. Educação em tempo integral. Oficineiros.

\section{FORMATION AND PRACTICE OF WORKSHOP TEACHERS IN FULL-TIME SCHOOLS}

\begin{abstract}
This article discusses some relevant aspects to understand the policies of integral education regarding to teacher education. We bring to the debate questions about the education and practices of workshop instructors in full-time schools based on a research developed on an integral education Program at the municipal level, in São Paulo state. Eighty - six workshop instructors who work at the Program took part in the

1 Doutorado em Educação. Professor Associado da Universidade Estadual Paulista - Unesp, Presidente Prudente, São Paulo, Brasil. Orcid iD: https://orcid.org/0000-0001-7772-6705. E-mail: renata.rinaldi@unesp.br

${ }^{2}$ Doutorado em Engenharia de Produção. Professor da Universidade Estadual Paulista Unesp, Presidente Prudente, São Paulo, Brasil. Orcid iD: https://orcid.org/0000-0002-1939-6223. E-mail: gilberto.rinaldi@unesp.br
\end{abstract}


research $(\mathrm{N}=86)$. The data collection procedure was the narrative register followed by the treatment and analysis using the Collective Subject Discourse (CSD) technique, developed with the support of the Qualiquantisoft software. The results showed that teacher education is not often addressed and that it is superficially discussed in the context of policy text production for integral education, which can point to "old" problems that are evident in the field of teacher education. For example, the development of continuing education strategies to fill the gap resulted from the inadequacy of initial education courses or even as a palliative to meet with the new demands of the school regarding the preparation of professionals who not always have a previous education and undertake the didactic-pedagogical activities in full-time schools.

Keywords: Teacher education. Integral education. Workshop teachers.

\section{FORMACIÓN Y PRÁCTICA DE TALLERISTAS EN ESCUELAS CON JORNADA}

\section{AMPLIADA}

\section{RESUMEN}

El artículo aborda algunos aspectos relevantes para la comprensión de las políticas de educación integral, en lo que se refiere a la formación de docentes. Traemos al debate preguntas sobre la formación y la práctica de los talleristas en escuelas de jornada ampliada, nos basamos en la investigación realizada en un programa educativo integral a nivel municipal, desarrollado en el estado de São Paulo. Ochenta y seis talleristas $(N=86)$ participaron en la investigación. El procedimiento de recolección de datos fue el registro narrativo, seguido del tratamiento y análisis utilizando la técnica del Discurso colectivo del sujeto (DSC), producida con el apoyo del software Qualiquantisoft. Los resultados mostraron que la formación docente es presentada de manera tímida y superficial en la producción de textos de políticas para la educación integral que pueden señalar problemas "antiguos" que son evidentes en el campo de la formación docente, por ejemplo, el desarrollo de estrategias de formación continuada para remediar los vacíos derivados de la inadecuación de los cursos de formación inicial o incluso como paliativos para satisfacer las nuevas demandas de la escuela con respecto a la preparación de profesionales, no siempre maestros con formación previa, que emprenden las actividades didáctico-pedagógicas en las escuelas con jornada ampliada.

Palabras clave: Formación docente. Educación integral. Talleristas.

\section{INTRODUÇÃO}

artigo discute, a partir das políticas de educação integral, alguns elementos que apontam como a formação de professores que atuam com a jornada ampliada tem sido concebida e desenvolvida no contexto escolar, em especial porque a realização das atividades pedagógicas nesses espaços tem sido concretizada por professores e outros profissionais 
que assumem a responsabilidade pela docência, chamados, em algumas realidades, de oficineiros, monitores, agentes culturais ou estagiários. Para tanto, analisa resultados de pesquisa ${ }^{3}$ realizada sobre um Programa de Educação Integral, desenvolvido em um município de médio porte no estado de São Paulo.

A pesquisa teve como objetivo central caracterizar e analisar o processo de implantação e desenvolvimento do Programa. Sua metodologia compreendeu o desenvolvimento de várias fases, a saber: a revisão de literatura, pesquisa documental (fontes primárias: esfera federal e municipal), entrevista e registro narrativo com os diversos atores do programa (gestores educacionais, gestores escolares, professores, oficineiros, estagiários, pais ou responsáveis, estudantes). Entre os resultados obtidos, verificamos a emergência de novos profissionais assumindo a docência no contraturno da escola com jornada ampliada, sem a devida preparação e qualificação profissional para o exercício do magistério. Essa constatação nos levou a tratar especificamente a problemática da formação e da prática docente de oficineiros que atuam nas escolas com jornada ampliada como foco deste artigo.

Para tanto, buscamos analisar como se dá a formação e a prática docente de oficineiros que atuam nas escolas municipais que implantaram o programa de educação integral no município de Presidente Prudente. Com base na literatura, inicialmente é apresentado o panorama da educação integral, relatando estudos que mostram as discussões sobre o tema. Em seguida, adentra-se a formação de professores com ênfase nas políticas de educação integral. Posteriormente, são apresentados os aspectos metodológicos da pesquisa e os resultados obtidos a partir dela.

\section{POLÍTICA DE EDUCAÇÃO (EM TEMPO) INTEGRAL: breves considerações}

O conceito de política pública pode ser considerado ambíguo, como destaca Rua $(2013$, p. 3), pois é "[...] impreciso, admite muitas definições e

\footnotetext{
3 Este artigo é resultado de pesquisa desenvolvida pela Rede Multidisciplinar de Pesquisa e
} Formação sobre Educação Integral (RMPFEI), com fomento da PROEX, CNPQ e FAPESP. 
algumas polêmicas. Essas divergências revelam discussões teóricas inconclusas, com autores importantes defendendo pontos, na maioria das vezes, irreconciliáveis". A autora concebe a política pública como "[...] o conjunto de procedimentos formais e informais que expressam relações de poder e que se destinam à resolução pacífica dos conflitos quanto aos bens públicos" (RUA, 2013, p. 5). Ainda de acordo com a autora, na maioria das vezes, a política pública implica mais do que uma decisão e demanda diversas ações estrategicamente selecionadas para implementar as resoluções tomadas.

Entretanto, apesar das inúmeras definições, assume-se o conceito apresentado por Santos $(2012$, p. 5), que define as políticas públicas como "[...] ações geradas na esfera do Estado e que têm como objetivo atingir a sociedade como um todo, ou partes dela". Para o autor, toda política pública possui uma intencionalidade e, para compreendê-la, é necessário considerar a identidade de seus formuladores e o contexto político, social, econômico e histórico em que foram elaboradas. Compreende-se, assim, a política pública como o Estado em ação, em que o mesmo estabelece e restabelece cursos e opta por determinadas ações e questões em detrimento de outras.

Há diferentes tipos de políticas públicas, entretanto, nas sociedades capitalistas ocidentais, cujos valores do Estado de Bem-estar social vingaram em todo ou em parte, foram desenvolvidas políticas de cunho social, visando à correção dos efeitos do capitalismo. A política social, segundo Abranches (1998, p. 14) é praticada na maioria dos países industrializados e busca, principalmente,

[...] compensar o mal-estar, os custos sociais, os efeitos perversos, derivados de ações indispensáveis à acumulação, de outras políticas governamentais e do próprio processo que, ao induzir mudanças, pode colocar certos grupos em situação de dependência.

Höfling (2001) insere a política social no interior de um tipo particular de Estado, vista como uma forma de interferência do Estado, visando à 
manutenção das relações sociais de determinada concepção social. Segundo a autora, as políticas sociais

[...] se referem às ações que determinam o padrão de proteção social implementado pelo Estado, voltadas em princípio, para a redistribuição dos benefícios sociais visando a diminuição das desigualdades estruturais produzidas pelo desenvolvimento socioeconômico (HÖFLING, 2001, p. 31).

Nesse contexto, sendo a política educacional um tipo de política social, ela corresponde a

[...] toda e qualquer política desenvolvida de modo a intervir nos processos formativos (e informativos) desenvolvidos em sociedade (seja na instância coletiva, seja na instância individual) e, por meio dessa intervenção, legitima, constrói ou desqualifica (muitas vezes de modo indireto) determinado projeto político, visando a atingir determinada sociedade (SANTOS, 2012, p. 3).

Desse modo, a política educacional está direcionada para a proposição de medidas que visam à formação do indivíduo enquanto cidadão. Saviani (2007, p. 1) acrescenta que a política educacional "[...] diz respeito, pois, à medida que o Estado, no caso, o governo brasileiro, toma relativamente aos rumos que se devem imprimir à educação no país".

No Brasil, temos acompanhado algumas mudanças e inúmeros retrocessos no âmbito das políticas públicas educacionais, mais recentemente podemos destacar: a proposta de programa para implantação de escolas cívico-militares; cortes asseverados no financiamento na área da Educação (que comprometem políticas, projetos e ações tanto na esfera da educação básica quanto da educação superior, mais fortemente atacada); Lei de Diretrizes e Bases da Educação Nacional, as Diretrizes Curriculares Nacionais (2006; 2015), Base Nacional Comum Curricular - BNCC (2017; 2018), Reforma do Ensino Médio (antes da aprovação da BNCC); Proposta de Emenda Constitucional - PEC n 15/2015 FUNDEB; entre inúmeras outras. 
No que se refere à educação integral em tempo integral como uma política educacional voltada à educação básica, Parente (2016, p. 265) destaca que

[...] a formulação e a implementação de uma política de educação integral em tempo integral no âmbito dos sistemas de ensino materializam o interesse do Estado em atuar nessa área. A ação do Estado e, portanto, as políticas públicas são permeadas de determinantes ao mesmo tempo em que também podem determinar e/ou condicionar outras ações do próprio Estado.

Segundo Silva (2017, p. 3), "Na história da educação brasileira, o tema da educação integral em tempo integral encontra-se presente de modo recorrente, embora seja utilizado a partir de matrizes ideológicas diferentes e às vezes antagônicas". Mais recentemente, a ampliação progressiva do tempo integral nas escolas e o direito à educação integral têm constado na agenda de políticas públicas educacionais nacionais, estaduais e municipais. No âmbito da esfera nacional, a educação integral tem sido incoporada à sua legislação em diversos documentos, a saber: Constituição Federal de 1988, Estatuto da Criança e do Adolescente - Lei nº. 8.069/1990, Lei de Diretrizes e Bases da Educação Nacional n. 9.394/96, Plano Nacional de Educação (PNE) - Lei n. 10.172/2001 e Lei n. 13.005/2014, Plano de Desenvolvimento da Educação - Compromisso Todos pela Educação Decreto n. 6.094/2007, Programa Mais Educação - Portaria Normativa Interministerial $n^{\circ}$. 17/2007, Decreto $n^{\circ}$. 7.083/2010, Programa Novo Mais Educação - Portaria MEC n 1.144/2016.

A concepção de educação integral como política pública para educação nacional começa a se caracterizar a partir do disposto na Constituição Federal de 1988 (BRASIL, 1988). A partir de então, outras legislações passaram não só a reafirmar a concepção de educação integral, mas também a traçar metas e estratégias para que ela fosse concretizada, sendo a ampliação da jornada escolar um dos meios encontrados para viabilizar esse propósito. A esse respeito, Jeffrey, Leite e Aguilar $(2018$, p. 3) afirmam que 
A política de educação integral, a partir do marco legal recente, também tem sido vinculada à educação de jornada ampliada, sendo que essa nomenclatura, em alguns momentos tem sido utilizada como sinônimo ou em outros para retratar a questão da formação integral do aluno (educação integral) e a ampliação do tempo escolar (educação de jornada ampliada).

Para Cavaliere e Coelho (2002), a relação entre a educação e o tempo se faz necessária quando se concebe uma educação transformadora e se almeja constituir um modelo de organização escolar vinculado a um projeto educacional efetivamente democrático. Entretanto, a ausência de clareza na legislação nacional sobre o que seria um ensino em tempo integral estimulou a discussão sobre educação integral e tempo integral. Como aponta Menezes (2012, p.140),

[...] a lei, ao não definir, estimulou a discussão entre os profissionais da educação sobre as contribuições, desafios e impactos do tempo integral no processo de formação dos alunos, além de fortalecer o debate sobre a relação entre educação integral e tempo integral, construindo assim, entre outros, subsídios a serem incorporados nas normatizações que se sucederam.

Nesse contexto, Menezes (2012, p. 141) ressalta que o Fundo de Manutenção e Desenvolvimento da Educação Básica e de Valorização dos Profissionais da Educação (FUNDEB) constituiu-se como "[...] divisor de águas no que tange à garantia do direito à educação em tempo integral", uma vez que o mesmo avançou em relação às leis anteriores.

A criação do Programa Mais Educação, instituído pela Portaria Interministerial $n^{\circ} 17 / 2007$ e regulamentado pelo Decreto $n^{\circ} 7.083 / 10$, foi considerada uma política educacional de indução de uma educação integral nas escolas brasileiras, cujo principal objetivo era

[...] contribuir para a formação integral de crianças, adolescentes e jovens, por meio da articulação de ações, de projetos e de programas do governo federal e suas contribuições às propostas, visões e práticas curriculares das redes públicas de ensino e das escolas, alterando o ambiente escolar e ampliando a oferta de saberes, métodos, processos e conteúdos educativos (BRASIL, 2007, p. 2). 
A estratégia proporciona a ampliação de tempo, espaços e oportunidades educacionais baseando-se no pressuposto da formação integral, sendo a mesma expressa pela articulação das aprendizagens da sala de aula, as vivências em oficinas de diversas áreas, os saberes comunitários que adentram a escola por meio de diferentes parcerias, a oferta de alimentação entre os turnos (VALENTINI; ZUCCHETTI, 2017).

O Programa Mais Educação atribuía à escola diversas finalidades, as quais abrangem:

I - [...] a ampliação do tempo e do espaço educativo e a extensão do ambiente escolar [...]; II - contribuir para a redução da evasão, da reprovação, da distorção idade/série, mediante a implementação de ações pedagógicas para melhoria de condições para 0 rendimento e o aproveitamento escolar; III - oferecer atendimento educacional especializado às crianças, adolescentes e jovens com necessidades educacionais especiais [...]; IV - prevenir e combater o trabalho infantil, a exploração sexual e outras formas de violência contra crianças, adolescentes e jovens [...]; $\vee$ - promover a formação da sensibilidade, da percepção e da expressão de crianças, adolescentes e jovens nas linguagens artísticas, literárias e estéticas [...]; VI - estimular crianças, adolescentes e jovens a manter uma interação efetiva em torno de práticas esportivas educacionais e de lazer [...]; VII - promover a aproximação entre a escola, as famílias e as comunidades [...] e; VIII - prestar assistência técnica e conceitual aos entes federados [...] (BRASIL, 2007).

Em linhas gerais, a partir de suas finalidades, verificamos uma designação à escola pública de uma dupla função de educar e proteger os estudantes, além de alterar significativamente a organização da educação escolar pública.

Em 2016, com a grave crise política que envolveu o país e culminou com o impeachment da presidenta eleita, aprovado pelo Senado Federal no dia 31 de agosto 4 daquele ano. A partir de então, o vice-presidente assumiu (e não mais de forma interina) o cargo da Presidência da República, de 01 de setembro de 2016 a 31 de dezembro de 2018, período em que aprofundou a desestabilização e a incerteza da continuidade das políticas públicas educacionais e programas, incluindo o Programa Mais Educação (PME), de modo que, em 2016, o PME foi interrompido, sendo retomado no

\footnotetext{
${ }^{4}$ No período de 12 de maio a 31 de agosto de 2016, a presidenta foi afastada e o então vice-presidente assumiu interinamente o cargo de Presidente da República.
}

Revista Exitus, Santarém/PA, Vol. 10, p. 01 - 28, e020026, 2020. 
final do mesmo ano com nova configuração, recebendo a nomenclatura de Programa Novo Mais Educação (PNME).

Instituído pela Portaria $n^{\circ} 1.144$ de 11 de outubro de 2016, o novo programa pertenceu à Secretaria de Educação Básica (SEB) e objetivou "[...] melhorar a aprendizagem em língua portuguesa e matemática no ensino fundamental, por meio da ampliação da jornada escolar de crianças e adolescentes [...]" (BRASIL, 2016, Art. 1\%). A execução do programa se deu por meio de articulação institucional e cooperação com as secretarias estaduais, distrital e municipais de educação, através do apoio técnico e financeiro do Ministério da Educação.

O novo programa previa a complementação da carga horária de cinco ou quinze horas semanais no turno e contraturno nas escolas públicas brasileiras. Caso a escola optasse por cinco horas de atividades, a mesma teria duas atividades de Acompanhamento Pedagógico (uma de Língua Portuguesa e uma de Matemática), com duas horas e meia de duração cada uma. Caso a escola fizesse a opção de quinze horas de atividades, duas atividades seriam de Acompanhamento Pedagógico (uma de Língua Portuguesa e uma de Matemática), com quatro horas de duração cada; e outras três atividades (atividades complementares do campo: artes, cultura, esporte e lazer) seriam realizadas nas sete horas restantes.

Podemos afirmar que as atividades complementares foram secundarizadas, considerando que, caso a escola optasse por desenvolver o programa ampliando o tempo escolar de modo a totalizar as cinco horas semanais, seria ofertado somente $\bigcirc$ Acompanhamento Pedagógico, constituído por atividades de Português e Matemática, nos levando a concluir que a finalidade formativa do Programa Novo Mais Educação não se direcionou para uma formação multidimensional, mas para uma formação escolar que possibilitasse melhores resultados dos estudantes em avaliações externas. 


\title{
Formação de professores e a política de educação (em tempo) integral
}

Vivemos um período intenso de mudanças no campo da educação; a formação de professores tem sido objeto de investigação de inúmeros estudos e o foco permanente das atuais políticas educacionais. Não raro se atribui indiscriminadamente o sucesso ou fracasso no desempenho do estudante à prática do professor e sua formação, sem considerar um contexto mais amplo e dinâmico, em que os fatores políticos, econômicos, históricos, sociais e culturais influenciam diretamente o resultado do trabalho docente.

Nesse cenário, Freitas (2014, p. 428) afirma que

\begin{abstract}
Ao examinar as diferentes metas e estratégias do PNE, identificamos uma lógica preocupante devido à perfeita articulação entre o sistema nacional de avaliação da educação básica - cuja centralidade já orientava a Lei de Diretrizes e Bases da Educação (LDB) e se mantém no atual Plano Nacional de Educação 2014-2024 - e as definições sobre formação inicial e continuada, o currículo e avaliação dos professores.
\end{abstract}

Essa realidade nos coloca o desafio premente de posicionamento político e luta num contexto de tensão permanente de disputas que se inserem, na contemporaneidade, no campo das políticas educacionais para a educação básica. Tratar dos desafios para as políticas de valorização e formação docente

[...] significa tomar como ponto de partida a concepção progressista de projeto educativo, a partir da qual a formação com qualidade elevada de pedagogos, educadores e professores está estreitamente vinculada à educação básica e à escola pública, às suas condições concretas e materiais atuais e ao seu pleno desenvolvimento e às possibilidades de uma educação emancipadora para nossas crianças, jovens e adultos na construção de uma sociedade justa e igualitária (FREITAS, 2014, p. 428).

Ao analisar a produção das políticas educacionais, como o Plano Nacional de Educação - PNE (BRASIL, 2014), a proposta do Programa mais educação (BRASIL, 2007; 2010) e Programa novo mais educação (BRASIL, 2016) e seus documentos orientadores, assim como o Plano Municipal de Educação (PRESIDENTE PRUDENTE, 2010; 2015), verificamos que a formação de professores não foi tratada ou aparece de maneira tímida e superficial, 
como é o caso do PNE, especificamente na Meta 6 que trata da Educação Integral, em que não há menção sobre a formação dos professores.

Os resultados verificados podem apontar para "velhos" problemas que se evidenciam no campo da formação de professores, por exemplo, a implementação de estratégias de formação continuada para remediar os vazios derivados da insuficiência dos cursos de formação inicial ou mesmo como um paliativo para atender às novas demandas da escola quanto à preparação dos profissionais, nem sempre professores com formação prévia, que assumem as atividades didático-pedagógicas no contraturno nas escolas com jornada ampliada.

\section{PROCEDIMENTOS METODOLÓGICOS}

\section{Caracterização da pesquisa}

A investigação adotou como princípio epistemológico a abordagem qualitativa, visto que os participantes da pesquisa, nas Ciências Humanas, "[...] são dotados de liberdade e consciência" (LAVILLE; DIONNE, 1999, p. 32). Para apreender a realidade dos fatos humanos é fundamental considerar que as pessoas atribuem sentido ao mundo que as rodeia. Contudo, é importante que a metodologia adote tanto uma abordagem teórica e documental quanto o trabalho de campo, alinhando-se à abordagem qualitativa cujo foco centra-se mais no processo do que nos resultados.

Desenvolvida no período de 2016-2019, a investigação atendeu aos preceitos éticos da pesquisa com seres humanos, conforme orienta a Resolução 510/2016 e respectivas normas operacionais e regimentais, aludidas pelo Comitê de Ética em Pesquisa da Universidade Estadual Paulista.

$\mathrm{Na}$ presente produção, especificamente, buscamos analisar a experiência com o I Seminário de Políticas de Educação Integral com o tema "Educação integral: política, experiências e os desafios de sua implementação", desenvolvido no segundo semestre de 2016 na cidade de Presidente Prudente. O principal objetivo do evento foi avaliar o programa 
de educação integral do município, intitulado Programa Cidadescola5, a partir da ótica de todos os segmentos envolvidos em sua implantação e desenvolvimento (gestores educacionais, gestores escolares, professores, oficineiros, estagiários, pais ou responsáveis, estudantes). O seminário teve a seguinte configuração:

QUADRO 1 - Programação do I Seminário de políticas de educação integral de Presidente Prudente/SP

\begin{tabular}{|c|c|c|c|}
\hline \multicolumn{2}{|l|}{ Atividade } & Convidados & Finalidade \\
\hline \multicolumn{2}{|c|}{$\begin{array}{l}\text { Apresentação Cultural } \\
\text { Cidadescola: "Dança" }\end{array}$} & $\begin{array}{l}\text { Estudantes do } \\
\text { Programa } \\
\text { Cidadescola }\end{array}$ & $\begin{array}{l}\text { Atividade desenvolvida pelos estudantes e } \\
\text { professores do Programa Cidadescola como } \\
\text { estratégia de apresentação aos pais e } \\
\text { comunidade dos trabalhos desenvolvidos no } \\
\text { programa, além do investimento na visibilidade } \\
\text { dos resultados obtidos e valorização dos } \\
\text { estudantes como protagonistas do processo da } \\
\text { educação integral. }\end{array}$ \\
\hline \multicolumn{2}{|c|}{ 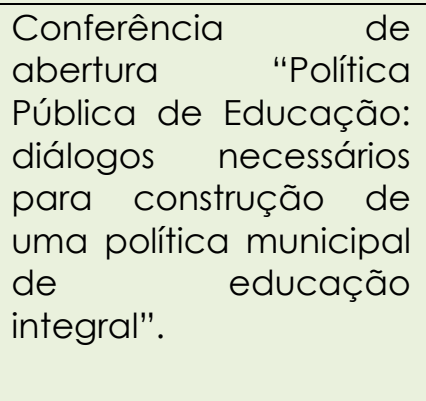 } & $\begin{array}{l}\text { Prof. Dr. Paulo } \\
\text { Sena Martins }\end{array}$ & $\begin{array}{l}\text { Conferência que versou sobre os atores e } \\
\text { políticas públicas educacionais adotadas em } \\
\text { escala municipal. Analisou com os participantes } \\
\text { a gênese e a implementação das políticas } \\
\text { educacionais, a partir da atuação de vários } \\
\text { atores: os Poderes do Estado - Executivo, } \\
\text { Legislativo e Judiciário -, os movimentos sociais } \\
\text { educacionais e as representações das esferas } \\
\text { federativas. }\end{array}$ \\
\hline \multicolumn{2}{|c|}{ Oficinas de Ludicidade } & $\begin{array}{l}\text { Estudantes } \\
\text { que } \\
\text { participaram } \\
\text { do Seminário }\end{array}$ & $\begin{array}{l}\text { Concomitante à conferência de abertura, os } \\
\text { estudantes do Programa Cidadescola foram } \\
\text { conduzidos a um espaço em que foram } \\
\text { desenvolvidas atividades lúdicas com os } \\
\text { principais objetivos de levar os participantes a: } \\
\text { compreender a importância do lúdico no } \\
\text { processo de interação e coletividade na } \\
\text { formação de valores (respeito, solidariedade } \\
\text { etc.); e valorizar o trabalho coletivo como meio } \\
\text { de superação de dificuldades ou limitações } \\
\text { individuais. As atividades foram coordenadas por } \\
\text { membros do CEPLIJ - Centro de Estudo e } \\
\text { Pesquisa em Educação, Ludicidade, Infância e } \\
\text { Juventude da Unesp/Campus de Presidente } \\
\text { Prudente. }\end{array}$ \\
\hline \multicolumn{2}{|c|}{$\begin{array}{lr}\text { Colóquio } & \text { com } \\
\text { estudantes } & \text { do } \\
\text { programa Cidadescola }\end{array}$} & Estudantes & $\begin{array}{l}\text { Relatos de experiências dos estudantes do } \\
\text { programa Cidadescola. }\end{array}$ \\
\hline \multicolumn{3}{|c|}{\begin{tabular}{|l|l|} 
Atividade & Conv \\
\end{tabular}} & Finalidade \\
\hline $\begin{array}{l}\text { Colóquio com } \\
\text { gestores, }\end{array}$ & $\begin{array}{l}\text { 1. G } \\
\text { 2. } P r\end{array}$ & $\begin{array}{l}\text { tores; } \\
\text { essores; }\end{array}$ & $\begin{array}{l}\text { 1. Relatos de experiências dos gestores } \\
\text { (Educacional e Escola) de Presidente Prudente. }\end{array}$ \\
\hline
\end{tabular}

${ }^{5}$ Informações adicionais sobre o programa e suas características serão detalhadas mais adiante, na seção Contexto da pesquisa. 


\begin{tabular}{|c|c|c|}
\hline $\begin{array}{l}\text { professores, } \\
\text { oficineiros, } \\
\text { estagiários e pais } \\
\text { ou responsáveis. }\end{array}$ & $\begin{array}{l}\text { 3. Oficineiros; } \\
\text { 4. Pais } \\
\text { responsáveis; } \\
\text { 5. Estagiários. }\end{array}$ & $\begin{array}{l}\text { 2. Relatos de experiências dos professores } \\
\text { do Programa Cidadescola. } \\
\text { 3. Relatos de experiências dos Oficineiros do } \\
\text { Programa Cidadescola. } \\
\text { 4. Relatos de experiência dos pais ou } \\
\text { responsáveis de/pelos estudantes do Programa } \\
\text { Cidadescola. } \\
\text { 5. Relatos de experiência dos Estagiários do } \\
\text { Programa Cidadescola. }\end{array}$ \\
\hline $\begin{array}{l}\text { Assembleia para } \\
\text { apresentação } \\
\text { das contribuições } \\
\text { de cada } \\
\text { segmento sobre o } \\
\text { tema da } \\
\text { educação } \\
\text { integral } \\
\text { sistematização } \\
\text { de documento } \\
\text { encaminhado ao } \\
\text { MEC. }\end{array}$ & \begin{tabular}{|lr} 
Participantes de & dos \\
todos & \\
segmentos & \\
(gestores, & \\
professores, & \\
oficineiros, \\
estagiários, pais ou \\
responsáveis).
\end{tabular} & $\begin{array}{l}\text { Elaboração de relatório descritivo-analítico sobre } \\
\text { a experiência do Programa Cidadescola, a partir } \\
\text { da ótica dos diversos atores. }\end{array}$ \\
\hline $\begin{array}{l}\text { Palestra de } \\
\text { encerramento "A } \\
\text { educação } \\
\text { integral no Brasil e } \\
\text { os desafios para } \\
\text { sua } \\
\text { implementação } \\
\text { por meio da } \\
\text { articulação entre } \\
\text { o sistema de } \\
\text { ensino, a escola e } \\
\text { a família" }\end{array}$ & $\begin{array}{l}\text { Eliane Ferraz - } \\
\text { Coordenadora do } \\
\text { Comitê } \\
\text { Metropolitano de } \\
\text { Educação Integral } \\
\text { da Região de } \\
\text { Campinas. } \\
\text { Luiz Carlos } \\
\text { Capellano Co - } \\
\text { Coordenador da } \\
\text { Educação Integral } \\
\text { do Município de } \\
\text { Campinas. }\end{array}$ & $\begin{array}{l}\text { A palestra de encerramento objetivou a } \\
\text { apresentação de experiências bem-sucedidas } \\
\text { de desenvolvimento da educação em tempo } \\
\text { integral no município de Campinas e na região } \\
\text { metropolitana de Campinas. }\end{array}$ \\
\hline
\end{tabular}

Fonte: os autores.

A realização do colóquio para os diferentes segmentos foi concebida por acreditamos que ele pode ser uma estratégia de trabalho coletivo que prioriza o debate democrático e a reflexão de um grupo de pessoas, a partir da mediação de um profissional, com o intuito de produzir conhecimento sobre a temática discutida, em que se almejava captar como cada segmento percebia a experiência do/no Programa Cidadescola.

Os colóquios foram mediados por docentes das universidades participantes da pesquisa que compõe a RMPFEl, acompanhados de estudantes do programa de pós-graduação em Educação da Unesp, campus de Presidente Prudente, e gravados integralmente em vídeos. Foram organizados em torno de dois momentos de reflexão: num primeiro 
momento, cada segmento foi separado em salas distintas, organizados inicialmente em pequenos grupos para discussão e registro escrito sobre o tema da educação em tempo integral, a partir das seguintes inquiriçõesb descritas no quadro 2.

QUADRO 2 - Inquirições norteadoras dos colóquios para os diversos segmentos

\begin{tabular}{|c|c|c|}
\hline $\begin{array}{c}\text { A escola que tivemos } \\
\text { (escola do passado) }\end{array}$ & $\begin{array}{c}\text { A escola que temos hoje } \\
\text { (escola do presente) }\end{array}$ & $\begin{array}{c}\text { A escola que queremos } \\
\text { (escola do futuro) }\end{array}$ \\
\hline & & \\
\hline
\end{tabular}

Fonte: os autores.

Em um segundo momento, houve, no próprio segmento, a socialização das reflexões tecidas pelos grupos, a partir da leitura do registro escrito; após a socialização e discussão das produções, cada segmento teve a incumbência de sistematizar um documento escrito contemplando o resultado das discussões e reflexões coletivas, além de indicar um representante para fazer a leitura pública do documento em assembleia.

Após o encerramento das atividades nos colóquios, todos os participantes foram convidados a retornar ao espaço do teatro, onde aconteceu uma assembleia que voltou a reunir todos os participantes do evento; na oportunidade, o representante escolhido por cada segmento fez a leitura pública do registro escrito com o resultado das discussões e reflexões do grupo. Após a leitura, os participantes debateram e se posicionaram sobre os resultados apresentados, referendando-os ou, em alguns momentos, refutando parcialmente algumas ideias. Esse momento se constituiu como um importante espaço de socialização das reflexões e experiências entre os atores que faziam/fazem parte do programa Cidadescola e culminou com a elaboração de um documento conjunto que seria enviado ao Ministério da Educação.

6 O planejamento e a confecção das inquirições norteadoras para elaboração do registro escrito foram realizados, conforme objetivos da pesquisa, bem como a realização de uma avaliação sobre a experiência de implantação e desenvolvimento do programa Cidadescola. 


\section{Contexto da pesquisa}

A pesquisa ocorreu na cidade de Presidente Prudente. O município pode ser caracterizado como de médio porte, com uma população estimada em 227.072 habitantes (IBGE, 2018). Está localizado a oeste da capital do estado de São Paulo, distando desta cerca de $558 \mathrm{~km}$.

FIGURA 1 - Localização de Presidente Prudente a extremo oeste do estado de São Paulo

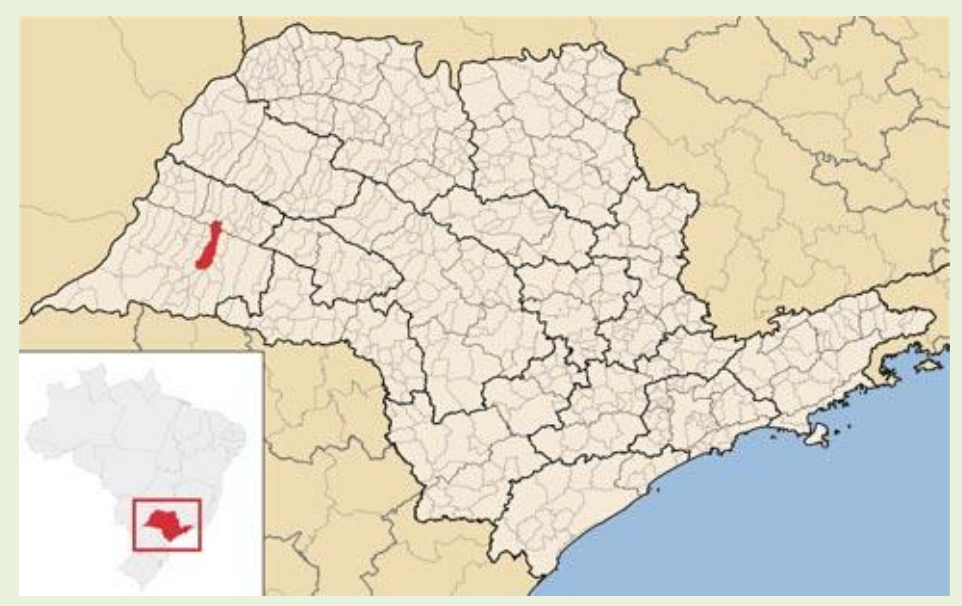

Fonte: IBGE, 2018.

O município tem como principais atividades econômicas a agropecuária e a indústria, em especial de micro e pequeno porte. Possui um Índice de Desenvolvimento Humano Municipal (IDH-M) de 0,806, considerado muito alto pelo Programa das Nações Unidas para o Desenvolvimento (PNUD), conforme se pode observar na tabela 1.

TABELA 1 - IDH geral, por renda, longevidade e sobre educação, município de Presidente Prudente/SP

\begin{tabular}{c|c|c|c}
\hline $\begin{array}{c}\text { IDH 2010 } \\
\text { Município }\end{array}$ & $\begin{array}{c}\text { IDH } \\
\text { Renda }\end{array}$ & $\begin{array}{c}\text { IDH } \\
\text { Longevidade }\end{array}$ & $\begin{array}{c}\text { IDH } \\
\text { Educação }\end{array}$ \\
\hline 0,806 & 0,788 & 0,858 & 0,774 \\
\hline
\end{tabular}

Fonte: PNUD, 2010.

O Índice de Desenvolvimento Humano (IDH) é um indicador criado pelo PNUD, órgão da Organização das Nações Unidas (ONU) que registra a qualidade de vida das populações por meio de indicadores econômicos e sociais, dentre eles a renda per capita, a taxa de escolaridade, o 
analfabetismo adulto e a expectativa de vida. A classificação do IDH é realizada a partir da seguinte escala: muito alto, alto, médio e baixo.

$O$ índice mensurado globalmente visa garantir a conscientização sobre o desenvolvimento humano e também fornece dados para se avançar, por exemplo, no desenvolvimento de políticas públicas e estratégias que permitam ampliar as capacidades e oportunidades das pessoas. No município de Presidente Prudente, o índice o situa na $25^{\mathrm{a}}$ posição entre os 5.565 municípios brasileiros, portanto, na faixa de IDH considerada muito alto.

$\mathrm{Na}$ figura 2, é possível observar $\mathrm{O} I \mathrm{DH}$ da cidade de Presidente Prudente comparado ao do estado de São Paulo e do Brasil, assim como do município de maior e de menor índice no país.

FIGURA 2 - Evolução comparativa do IDH de Presidente Prudente

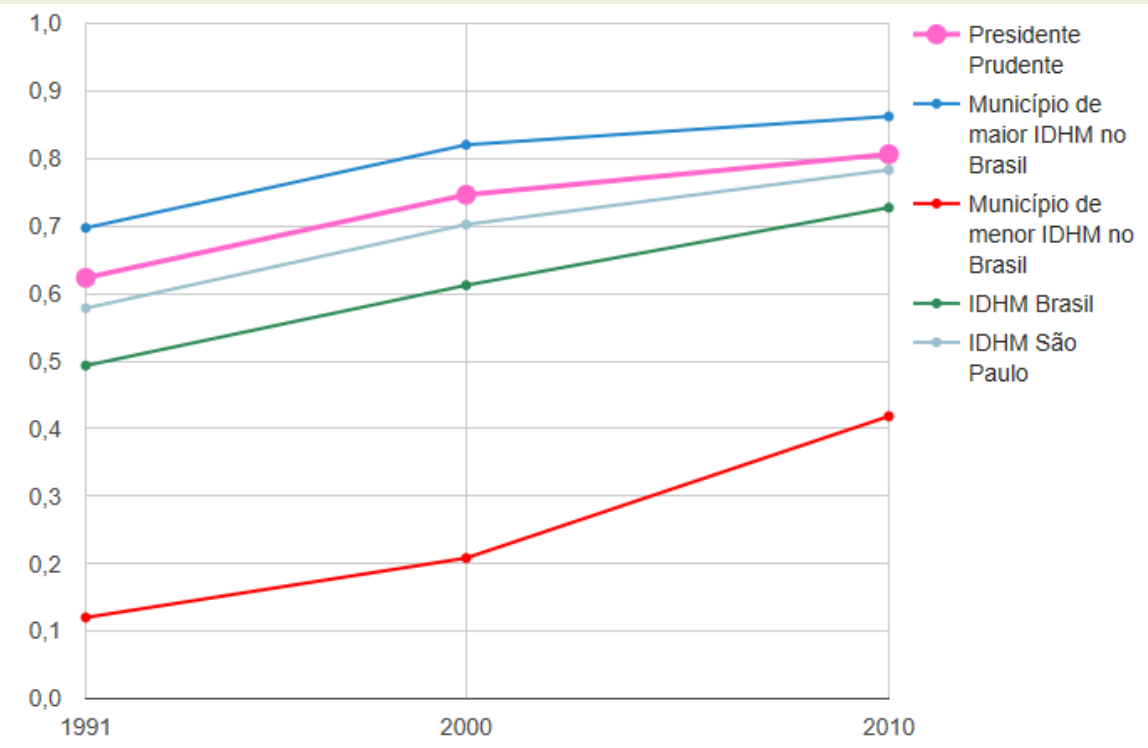

Fonte: PNUD, 2010.

No âmbito educacional, o município atende toda a educação básica (educação infantil, ensino fundamental e ensino médio), assegurada pelo ensino público e privado. A educação infantil (creche e pré-escola) e o ensino fundamental $1\left(1^{\circ}\right.$ ao $5^{\circ}$ ano) públicos estão inteiramente sob a responsabilidade do município. O ensino fundamental II ( $6^{\circ}$ ao $9^{\circ}$ ano) e o ensino médio públicos estão sob a responsabilidade do Estado de São Paulo. 
Também está sob a responsabilidade do município e do estado a oferta pública da Educação de Jovens e Adultos $\left(1^{\circ}\right.$ ao $5^{\circ}$ ano e $6^{\circ}$ ao $9^{\circ}$ ano e $o$ ensino médio, respectivamente). A educação superior é ofertada por uma universidade pública estadual, uma privada, dois centros universitários privados e aproximadamente 20 polos universitários de iniciativa privada, com a oferta de educação à distância/semipresencial.

O município de Presidente Prudente, em 17 de agosto de 2010, implantou, por meio do Decreto $n^{\circ}$. 21.142/2010, um projeto piloto de educação integral, denominado Programa Cidadescola, com o objetivo de desenvolver a formação integral das crianças que frequentam $\circ$ Ensino Fundamental I ( $1^{\circ}$. ao $5^{\circ}$ ano) e contribuir para a realização de propostas e práticas curriculares, ampliando a oferta de saberes e de atividades socioeducativas que auxiliem no processo de formação das crianças, por meio da articulação de ações intersetoriais de todas as Secretarias e órgãos municipais, incluindo os campos da Educação, Artes, Cultura, Esporte, Lazer, Meio ambiente, Saúde e outros. O programa recebeu esse nome por ter uma proposta de envolver os diferentes setores sociais nas atividades educativas e por considerar que a cidade, por meio de seus espaços públicos, também educa.

A ampliação da jornada educativa deve ser igual ou superior a sete horas diárias e ofertar atividades diversificadas às crianças e adolescentes no contraturno escolar, sendo algumas delas: acompanhamento pedagógico referentes à língua portuguesa e matemática, meio ambiente, esporte e lazer, cultura e arte, prevenção e promoção à saúde. Em 2016, estava implantado nas 31 escolas de anos iniciais do ensino fundamental do sistema municipal de ensino e atendia a 2.909 estudantes na faixa etária de 6 a 10 anos de idade.

\section{Participantes da pesquisa}

A pesquisa envolveu os atores da escola e do sistema municipal de ensino que participaram/participam da implantação e ampliação da jornada escolar no município, a saber: estudantes do $1^{\circ}$ ao $5^{\circ}$ ano, pais ou 
responsáveis, oficineiros, estagiários, professores, gestores escolares e gestores educacionais. Para o presente artigo, centraremos as análises nos profissionais que exerciam a função de oficineiros e participaram do evento em 20167. No total, o município tinha contratado para essa função 105 oficineiros que foram convocados para participar do evento, todavia, 86 participaram das atividades, aproximadamente $82 \%$ dos profissionais.

De modo geral, no quadro 3, podemos observar o perfil dos profissionais que ocupavam a função de oficineiros.

QUADRO 3 - Profissionais oficineiros atuantes no Programa Cidadescola

\begin{tabular}{|c|c|c|}
\hline Profissionais & Formação & Observação \\
\hline $\begin{array}{l}\text { Professor de Educação Física } \\
\text { da Secretaria Municipal de } \\
\text { Educação-SEDUC }\end{array}$ & $\begin{array}{l}\text { Graduação } \\
\text { Educação Física }\end{array}$ & \\
\hline $\begin{array}{l}\text { Professor } \\
\text { contratada para oficina de } \\
\text { Música }\end{array}$ & $\begin{array}{l}\text { Ensino médio e curso de } \\
\text { instrumentos musicais }\end{array}$ & \\
\hline $\begin{array}{l}\text { Oficineiros contratados pelo } \\
\text { Programa Mais Educação }\end{array}$ & $\begin{array}{l}\text { Estudantes Universitários e } \\
\text { profissionais da área de } \\
\text { Artes }\end{array}$ & $\begin{array}{l}\text { Contratados para } \\
\text { turmas de } 25 \text { alunos. }\end{array}$ \\
\hline $\begin{array}{lll}\begin{array}{l}\text { Oficineiros } \\
\text { Intersetorial }\end{array} & \text { da } & \text { Parceria } \\
\end{array}$ & \begin{tabular}{ll|} 
Graduação & em \\
Educação Física & \\
\end{tabular} & $\begin{array}{l}\text { Atuam nas oficinas de } \\
\text { handball, karatê, futsal. }\end{array}$ \\
\hline $\begin{array}{l}\text { Professores efetivos que } \\
\text { recebem carga suplementar }\end{array}$ & $\begin{array}{l}\text { Graduação } \\
\text { Pedagogia }\end{array}$ & $\begin{array}{l}\text { Professores da própria } \\
\text { escola que recebem } 75 \\
\text { horas de carga } \\
\text { suplementar para atuar } \\
4 \text { dias por semana em } \\
\text { até duas oficinas. }\end{array}$ \\
\hline $\begin{array}{lcr}\text { Professor da } & \text { empresa } \\
\text { contratada para as oficinas } \\
\text { de } & \text { práticas } \\
\text { esportivas/natação } & \end{array}$ & $\begin{array}{l}\text { Graduação } \\
\text { Educação Física }\end{array}$ & \\
\hline
\end{tabular}

Fonte: Relatório SEDUC, 2015.

Além de informações gerais sobre o perfil do profissional que ocupava a função, também são apresentadas informações adicionais que nos possibilitam compreender as suas condições de trabalho.

\footnotetext{
7 Os oficineiros foram organizados inicialmente em seis pequenos grupos, sendo dois com quinze e quatro com quatorze participantes.
} 


\title{
Procedimentos para a coleta de dados
}

A coleta de dados analisados na presente produção ocorreu a partir do registro escrito produzido pelos participantes durante o I Seminário de Políticas de Educação Integral, em setembro de 2016, concebidos como registro narrativo. Foram elaborados a partir de inquirições norteadoras para realização do trabalho nos colóquios nos diversos segmentos. Esse tipo de instrumento foi compreendido como propõe Abrahão (2011, p. 172), quando afirma:

\begin{abstract}
Sempre que aqui estivermos tratando de narrativa, estamos nos referindo ao que denomino "narrativa de vida", "narrativa autorreferente", "narrativa na primeira pessoa", ou ainda, como se lê em alguns autores, "narrativa autobiográfica" e "narrativa de si". Isso porque não se trata de uma narrativa pura e simples a respeito de quaisquer fatos, e sim da narrativa de acontecimentos que afetam/afetaram os sujeitos da narração e que, reflexionados no momento narrativo, vão se revestindo, mediante o evocar de imagens-lembranças/recordações/referências, de novo significadode um entendimento mais ampliado e esclarecido - para o narrador.
\end{abstract}

Para Lefèvre e Lefèvre (2011), o homem, como um atribuidor de sentidos, gera conhecimento nas interações com outros sujeitos com os quais tenha um sistema compartilhado de ideias. Ao concordar com os autores, buscamos entender os sentidos atribuídos pelos oficineiros aos relatos de formação e prática docente no colóquio durante o seminário.

Para análise dos dados nos pautamos na técnica do Discurso do Sujeito Coletivo - DSC (LEFÈVRE; LEFÈVRE, 2000), que é uma metodologia de organização e tabulação de dados qualitativos de natureza verbal, obtidos a partir de depoimentos com o principal objetivo de apreender a experiência. Significa dizer que

[...] a proposta consiste basicamente em analisar o material verbal coletado, extraído de cada um dos depoimentos. O Discurso do Sujeito Coletivo é uma modalidade de apresentação de resultados de pesquisas qualitativas, que tem depoimentos como matéria prima, sob a forma de um ou vários discursos-síntese escritos na primeira pessoa do singular, expediente que visa expressar o pensamento de uma coletividade, como se esta coletividade fosse o emissor de um discurso (LEFÈVRE; CRESTANA; CORNETTA, 2003, p. 70). 
Os registros narrativos coletados foram tratados metodologicamente por meio do software Qualiquantisoft8 com o intuito de obter o pensamento coletivo sobre como se dá a formação e a prática docente de oficineiros que atuam nas escolas municipais que implantaram o programa de educação integral no município de Presidente Prudente.

Os resultados são apresentados e discutidos a seguir, sob a forma de discursos-síntese escritos na primeira pessoa do singular, expressando o pensamento dos oficineiros que participaram do I Seminário de Políticas de Educação Integral.

\section{RESULTADOS E DISCUSSÕES}

Os oficineiros participantes do colóquio destacaram inicialmente os desafios para o desenvolvimento do programa Cidadescola. Após o tratamento das ideias-chave, obtivemos o seguinte DSC:

Para mim a infraestrutura é insuficiente ou inadequada para desenvolvimento das oficinas, faltam recursos materiais como instrumentos musicais e didáticos para as oficinas visando ao desenvolvimento pleno do trabalho do oficineiro. Eu vejo a ausência da participação da família nas atividades do Programa e no apoio ao professor oficineiro. Para mim, esse espaço é muito importante porque não tem momento em que os oficineicos podem falar dentro da escola. Acho difícil quando a oficina acontece fora da escola e precisa do transporte (DSC, 2016).

Esse DSC explicita os desafios de natureza diversa que os oficineiros encontram nas escolas em que atuam. Abrangem desde aspectos de infraestrutura e recursos materiais, como também de planejamento estratégico e pedagógico envolvendo a organização de espaço e do tempo escolar que privilegiem a formação desses profissionais e a aproximação com as famílias. Parente (2006, p. 142) afirma:

[...] ao mudarmos o foco de discussão de escola em tempo integral para educação em tempo integral, estamos entendendo as relações intrínsecas estabelecidas pela escola com outras

8 O Qualiquantisoft é um programa desenvolvido com base na teoria do Discurso do Sujeito Coletivo, que, segundo Lefèvre e Lefèvre (2012), permite o processamento de dados para a análise de recortes discursivos por meio da criação de um banco de dados que filtra os discursos em estratos e os compara. 
instituições, organizações e movimentos sociais, bem como a própria ampliação do conhecimento, das ações e dos espaços escolares. Todos esses elementos, acredita-se, condicionam os tempos da escola.

Ainda, resultados similares foram encontrados por autores em realidades diversas que verificaram em seus estudos: condições precárias no desenvolvimento de programas de tempo integral nos estados e municípios, como as condições estruturais das escolas, os obstáculos à universalização da proposta de ampliação da jornada a todos os estudantes, tendência em se priorizar os municípios, escolas e alunos com maior vulnerabilidade social, pulverização das atividades por diversos ambientes (CLEMENTINO; OLIVEIRA, 2017; KAVAI, 2013; COELHO, 2012; COSTA, 2011).

Os oficineiros também destacaram que a prática docente se configura de modo desafiador e de maneira precária em algumas escolas. Por exemplo, quando

[...] sei que a família nem sempre está presente e transferiu a responsabilidade do educar para a escola. Eu acho que os diretores não compreendem que o programa e a escola são uma coisa só. Pois, são os mesmos alunos [e] é necessária uma integração total. [...] Acredito que é necessário que o tempo integral seja realmente integrado vendo o ensino como um todo em não em turno regular e Cidadescola (DSC, 2016).

Observa-se no DSC que participar do evento, e especificamente do colóquio, parece ter se constituído um importante momento formativo, de troca de experiências e avaliação sobre o programa. Os profissionais apresentam em suas narrativas problemas que influenciam a prática de ensino e o trabalho do professor, como a falta de articulação do currículo e de integração entre os professores e os profissionais da escola. No DSC não se percebe de que forma a prática de ensino dos oficineiros se configura, é planejada, assim como o objetivo de uma educação integral será desenvolvido na formação do estudante.

De fato, cabe destacar que o processo de ensino abrange a sequência de atividades do professor, compreende o planejamento, a organização, a direção, até a avaliação da atividade didática, a fim de 
que o aluno desenvolva a assimilação dos conhecimentos e habilidades. Tendo em vista que o trabalho docente é de mediação entre aluno e matérias de ensino, ele não é uma mera transmissão, mas uma fonte de organização dos estudos dos alunos. Para Libâneo (2013, p. 5), os objetivos dos alunos devem ser condizentes com o do professor e afirma que "[...] 0 ensino somente é bem-sucedido quando os objetivos do professor coincidem com os objetivos de estudo do aluno e é praticado tendo em vista o desenvolvimento das suas forças intelectuais".

Segundo os participantes, nos registros narrativos sobre a formação do grupo investigado, o DSC evidencia que ela acontece de modo tímido e insuficiente para o desenvolvimento de um trabalho docente de qualidade.

\begin{abstract}
Tenho uma multiplicidade de atividades na função de professor: educar, cuidar e ensinar. Não tenho acesso aos cursos de capacitação gratuitos para oficineiros. Não tem valorização dos profissionais Oficineiros. Não há integração de todos os profissionais sem diferença de ser do ensino regular e do programa cidadescola. Não sou formado para tudo isso. É necessária a elaboração de documento que dê um norte para cada oficineiro de como conduzir suas aulas. Falta planejamento e orientação para ensinar no programa (DSC, 2016).
\end{abstract}

De acordo com Freitas (2014), esses são desafios que devemos enfrentar. Há profissionais que assumiram a função docente nas oficinas do Programa Cidadescola sem ter cursado ou concluído um curso de formação inicial de professor. Essa realidade aponta para a precarização da educação pública e para o trabalho docente. Mais alarmante é observar que não só a formação inicial é frágil ou inexistente entre os Oficineiros, mas também outros aspectos que envolvem a formação continuada, as condições de trabalho, remuneração etc. e são apresentadas nas reflexões sobre a docência no programa.

Ao pensar sobre sua formação e prática na atuação como oficineiro na escola com jornada ampliada no município de Presidente Prudente/SP, o profissional reflete sobre a experiência vivida e essa reflexão "[...] pode ser considerada uma estratégia importante para a docência, visto que permite encontrar caminhos para o aprimoramento da prática e descobrir acertos e 
erros do trabalho educacional para construir novos rumos de atuação" (CARABETTA JÚNIOR, 2010, p. 582).

\section{CONSIDERAÇÕES FINAIS}

Este estudo revela, com base nos documentos analisados do município, que o Programa Cidadescola, apoiado em uma proposta de educação integral, exige a participação ativa de todos os segmentos, em especial dos professores. São eles os profissionais que atuam com o aluno e ao mesmo tempo têm os conhecimentos específicos das diversas áreas do saber envolvidos na construção dos conhecimentos do ensino, lidam cotidianamente com a realidade e as demandas apresentadas pelos estudantes. Dessa forma, os professores estão em posição privilegiada para pensar a proposta de uma educação integral.

Em primeiro lugar, entende-se que uma proposta de implantação da educação integral nas escolas de ensino fundamental do Sistema Municipal de Ensino que se propõe como uma alternativa de/para a melhoria da qualidade da educação ofertada requer profissionais com formação adequada para assumir tamanha responsabilidade. Entretanto, outros aspectos precisam ser considerados nesse processo, a saber: condições de trabalho, remuneração, carreira etc.

Em segundo lugar, qualquer proposta educativa de implantação da educação integral que implicará em mudanças na organização do Sistema de Ensino, nas escolas e na prática docente desafia os professores a compreenderem o que é educação integral, o que é educação em tempo integral e o que é jornada ampliada nos planos teórico e prático. Isto implica em considerar o conhecimento: de documentos oficiais, por exemplo, como políticas educacionais e documentos orientadores; da realidade do Sistema de Ensino, bem como daquela em que a escola se insere e seus alunos; escolar, com suas inúmeras dinâmicas internas, num contexto de investigação que reconhece a articulação entre a concepção de educação e de conhecimento e entre o método de ensino que $\circ$ professor utiliza para selecionar os encaminhamentos metodológicos e avaliativos. 
Em terceiro lugar, os professores que ałuaram no contexto da ampliação da jornada escolar analisado eram, em sua maioria, oficineiros. Nem sempre esses profissionais que assumiram as atividades didático-pedagógicas no contraturno nas escolas tinham cursado ou mesmo concluído a formação inicial em nível superior relativa à docência. As suas práticas de ensino se concentraram mais numa dimensão técnica de transmissão (ensino) do conteúdo trabalhado por meio das oficinas curriculares que envolveram atividades de diversos campos do saber como: artes, cultura, esporte e lazer. Entretanto, a ênfase foi dada ao trabalho com os componentes curriculares, por meio da oficina de Orientação de Estudo e Leitura (OEL), sempre sob a responsabilidade de um professor efetivo do Sistema Municipal de Ensino.

Foi possível identificar o apontamento de inúmeros aspectos que dificultam a prática de ensino do professor oficineiro, por exemplo: problemas com infraestrutura e materiais didáticos, ausência de interesse das crianças pelo programa, falta de apoio, participação e valorização por parte das famílias, precarização do trabalho docente e falta de reconhecimento do oficineiro como professor etc. Além disso, percebeu-se que o objetivo prioritário do programa se restringe à melhoria do desempenho educacional das crianças e não à preocupação com uma formação integral e crítico-emancipatória desse sujeito.

Em quarto lugar, a formação de professores aparece de maneira tímida e superficial na produção de textos das políticas para educação integral, tanto na esfera federal quanto na municipal. A mesma "fragilidade" também se verifica no material produzido pelos participantes, que apontaram de modo bastante genérico a ausência de "capacitação" e investimento na formação continuada dos oficineiros, bem como de materiais de orientação para o trabalho em sala de aula. Nesse sentido, os dados revelam a necessidade de desenvolvimento de estratégias de formação continuada para remediar os vazios derivados da insuficiência dos cursos de formação inicial ou mesmo como um paliativo para atender às novas demandas da escola quanto à preparação dos professores oficineiros, também fruto de um processo de precarização do trabalho docente. 
De modo geral, observamos, ainda, críticas bastante agudas que precisam ser levadas em consideração para continuidade do Programa Cidadescola. Finalmente, cabe destacar que o procedimento usado na coleta de dados empíricos mostrou-se um processo valioso, pois gerou dados primários, que, na qualidade de feedback, podem ser úteis à pesquisa e ao desenvolvimento do programa de educação integral do município. Também se configurou como um espaço de formação continuada dos oficineiros, que avaliam a oportunidade de dialogar com os pares sobre a formação (ou ausência dela) e suas práticas no programa como muito positiva e que deveria ocorrer com mais frequência.

Os resultados indicam para o contexto da formação de professores e da prática de ensino a necessidade de conhecimento e compreensão das políticas educacionais de Educação Integral - e também da formação de professores -, de âmbito nacional e municipal, para um posicionamento político e pedagógico de enfrentamento do processo de desmantelamento que tem sido imprimido no campo da educação, em especial da formação docente.

\section{REFERÊNCIAS}

ABRANCHES, S. H. Política social e combate à pobreza: a teoria da prática. In: COIMBRA, Marcos Antônio; SANTOS, Wanderley Guilherme dos ABRANCHES, Sérgio Henrique. Política social e combate à pobreza. Rio de Janeiro: Jorge Zahar, 1998. p. 9-31.

BRASIL. Ministério da Educação. Programa Novo Mais Educação: Documento orientador - Adesão - versão 1. Brasília, DF: MEC, Out/2016. Disponível em http://portal.mec.gov.br/docman/dezembro-2016-pdf/53061-novo-maiseducacao-documento-orientador-pdf/file. Acesso em: 2 mar. 2018.

BRASIL. Portaria $n^{\circ} 1.144$, de 11 de outubro de 2016. Institui o Programa Novo Mais Educação. Diário Oficial da União, Brasília, DF, 11 de outubro de 2016. Disponível em: http://portal.mec.gov.br/docman/outubro-2016-pdf/49121port-1145-11 lout-pdf/file. Acesso em: 16 mar. 2018.

BRASIL. Lei no 13.005, de 25 de junho de 2014. Aprova o Plano Nacional de Educação (PNE) e dá outras providências. Diário Oficial da União, Brasília, 26 jun. 2014. Disponível em:

http://pesquisa.in.gov.br/imprensa/jsp/visualiza/index. 
jsp? data $=26 / 06 / 2014 \&$ jornal $=1000 \&$ pagina $=1$ \& total Arquivos=8. Acesso em: 15 mar. 2018.

BRASIL. Decreto $n^{\circ} .7 .083$, de 27 de janeiro de 2010. Dispõe sobre o Programa Mais Educação. Diário Oficial da União, Brasília, DF, 27 jan. 2010. Disponível em: https://www.planalto.gov.br/ccivil_03/_ato2007-

2010/2010/decreto/d7083.htm. Acesso em: 22 fev. 2018.

BRASIL. Ministério da Educação. Portaria Normativa Interministerial $n^{\circ} 17$, de 24 de abril de 2007. Institui o Programa Mais Educação. Diário Oficial da União, Brasília, DF, 26 abr. 2007. Disponível em: http://portal.mec.gov.br/docman/outubro-2016-pdf/49131-port-1144maiseduc-pdf/file. Acesso em: 12 mar. 2018.

CARABETTA JÚNIOR, Vr. Rever, pensar e (re) significar: a importância da reflexão sobre a prática na profissão docente. Revista Brasileira de Educação Médica, v. 34, n. 4, p. 580-586, 2010. Disponível em: http://www.scielo.br/pdf/rbem/v34n4/v34n4al4.pdf. Acesso em: 07 out. 2019.

CAVAlieRE, A. M.; COELHO, L. M. C. da C. Perfil de 50 CIEPs estaduais em 2001. Rio de Janeiro: NEEPHI; UNIRIO, 2002. (Relatório de pesquisa).

CLEMENTINO, A. M.; OLIVEIRA, D. A. Novos sujeitos docentes e suas condições de trabalho: uma comparação entre o Programa Escola Integrada e o Projeto Educação em Tempo Integral. Em Aberto, Brasília, v. 30, n. 99, 2017. Disponível em: http://emaberto.inep.gov.br/index. php/emaberto/article. Acesso em 10 de jan. 2018.

COELHO, L. M. C. da C. Alunos no ensino fundamental: ampliação da jornada escolar e educação integral. Educar em revista, n.45, p.73-89, 2012. Disponível em: http://www.scielo.br/pdf/er/n45/06.pdf. Acesso em: 17 jan. 2020.

COSTA, C. S. N. et al. Política cultural e desenvolvimento: uma análise do Programa Bairro Escola, do município de Nova Iguaçu. Cadernos EBAPEBR, Rio de Janeiro, v. 9, n. 4, 2011 . Disponível em: www.scielo.br/scielo. Acesso em 17 jan. 2020.

FREITAS, H. C. L. de. PNE e formação de professores: contradições e desafios.

Retratos da Escola, v.8, n. 15, p. 427-446, jul./dez., 2014. Disponível em: http://retratosdaescola.emnuvens.com.br/rde/article/viewFile/451/582. Acesso em 17 jan. 2020.

Instituto Brasileiro de Geografia e Estatística - IBGE. (2018). População. Disponível em: https://cidades.ibge.gov.br/brasil/sp/presidenteprudente/panorama. Acesso em13 abr. 2019. 
HÖFLING, E. de M. Estado e políticas (públicas) sociais. Caderno CEDES, Campinas, v. 21, n. 55, p. 30-41, nov. 2001. Disponível em: http://www.scielo.br/scielo.php?script=sci_arttext\&pid=\$0101$32622001000300003 \&$ Ing=en\&nrm=iso. Acesso em 07 set. 2019.

JEFREY, D. C.; LEITE, S. F.; AGUILAR, L. E. (Orgs.). Seminário do Grupo de Estudos e Pesquisas em Política Educacional e Avaliação (GEPALE), 3, Anais... Campinas: FE/UNICAMP, 2018.

\section{KAVAI, S. H. G. R. O Programa Mais Educação em Duque de Caxias/RJ:}

Analisando uma política de ampliação da jornada escolar. 127 f. Dissertação (Mestrado em Educação). Universidade Federal do Rio de Janeiro, Rio de Janeiro, 2013.

LAVILLE, C.; DIONNE, J. A construção do saber: manual de metodologia da pesquisa em ciências humanas. Belo Horizonte: Artmed/UFMG, 1999.

LEFÈVRE, F.; LEFÈVRE, A. M. C.; TEIXEIRA, J. J. V. O discurso do sujeito coletivo: uma nova abordagem metodológica em pesquisa qualitativa. Caxias do Sul: EDUCS, 2000.

LEFÈVRE, A. M. C.; CRESTANA, M. F.; CORNETTA, V. K. A utilização da metodologia do discurso do sujeito coletivo na avaliação qualitativa dos cursos de especialização "Capacitação e Desenvolvimento de Recursos Humanos em Saúde-CADRHU", São Paulo - 2002. Saúde e Sociedade, v.12, n.2, p.68-75, jul-dez 2003.

LEFÈVRE, F.; LEFÈVRE, A. M. C. Curso teórico prático de introdução ao discurso do sujeito coletivo e ao software QualiQuantiSoft. São Paulo: Instituto de Pesquisa do Discurso do Sujeito Coletivo (IpDsc), 2011.

LIBÂNEO, J. C. Políticas educacionais em discussão no Brasil: o lugar do currículo e da didática. Revista APASE (São Paulo), v. 1, p. 6-90, 2013.

MENEZES, J. S. da S. Educação em tempo integral: direito e financiamento. Educar em revista, Curitiba, n. 45, p. 137-152, set. 2012. Disponível em: http://www.scielo.br/scielo.php?script=sci_arttext\&pid=S0104$40602012000300010 \&$ Ing=en\&nrm=iso. Acesso em: 17 jan. 2020.

PARENTE, C. da M. D. A construção dos tempos escolares: possibilidades e alternativas plurais. 2006. $173 \mathrm{f}$. Tese (Doutorado em Educação) - Faculdade de Educação, Universidade Estadual de Campinas, Campinas, SP, 2006.

PRESIDENTE PRUDENTE. Decreto $\mathbf{n}^{\circ} \mathbf{2 1 . 1 4 2}$, de 17 de agosto de 2010. Dispõe sobre a instituição do Programa Cidadescola. Presidente Prudente, SP, 2010. Disponível em: 
http://www.presidenteprudente.sp.gov.br/site/Documento.do? cod=16699. Acesso em: Acesso em 20 mar. 2018.

PRESIDENTE PRUDENTE. Lei $\mathbf{n}^{\circ} \mathbf{8 . 9 6 2 / 2 0 1 5}$, de $\mathbf{3}$ de novembro de 2015. Aprova o Plano Municipal de Educação - PME, e dá outras providências. Presidente Prudente, SP, 2015. Disponível em:

http://www.presidenteprudente.sp.gov.br/site/Documento.do? cod=25533. Acesso em: Acesso em 20 mar. 2018.

RINALDI, R. P. Rede de pesquisa e formação sobre educação integral: experiências, movimentos, inovação e desafios contemporâneos. Projeto de pesquisa. Universidade Estadual Paulista, Presidente Prudente, 2016. (Mimeo)

RINALDI, R. P.; SILVA, N. S. da. Educação integral: entre o passado e o futuro. Educação em Revista, Marília, v.18, p. 121-138, 2017, Edição Especial. Disponível em: http://www2.marilia.unesp.br/revistas/index.php/educacaoemrevista/article/ viewFile/6777/4420. Acesso em: 15 maio 2018.

RUA, M. das G. Para aprender políticas públicas. Brasília, DF: IGEPP, 2013.

SANTOS, P. S. M. B. dos. Estruturas, conceitos e fundamentos da política educacional. In: SANTOS, P. S. M. B. dos. Guia Prático da Educação no Brasil: ações, planos, programas e impactos. São Paulo: CENGAGE Learning, 2012.

SAVIANI, D. Da nova LDB ao FUNDEB: por uma outra política educacional. Campinas, SP: Autores Associados, 2007.

SILVA, B. A. R. da. A predominância da vertente "alunos em tempo integral" nas discussões sobre o tema da educação integral em tempo integral.

Revista Brasileira de Educação, v. 22, n. 71, e227170, p. 1-25, 2017. Disponível em: http://dx.doi.org/10.1590/S1413-24782017227170. Acesso em: 14 nov. 2018.

VALENTINI, C. A.; ZUCCHETTI, D. T. A educação integral no Brasil: das experiências históricas ao programa mais educação. Comunicações, Piracicaba, v. 24, n. 2, p. 199-214, maio-agosto 2017. Disponível em: https://www.metodista.br/revistas/revistasunimep/index.php/comunicacoes/ article/view/2825. Acesso em: 05 mar. 2018.

Recebido em: 07 de outubro de 2019 Aprovado em: 13 de janeiro de 2020 